\title{
LIRIK TEMBANG SUNDA CIGAWIRAN (Kajian Historis, Struktural, dan Etnopedagogik)
}

\author{
Dian Astriani, Dedi Kosawara \\ SMP Negeri 2 Cibiuk \\ Pos-el: dianastriany@gmail.com, dedi.koswara@upi.edu
}

\begin{abstract}
Abstrak
Tujuan penelitian ini mendeskripsikan perkembangan, struktur, dan nilai étnopédagogik lirik tembang Sunda Cigawiran. Metode yang digunakan dalam penelitian ini adalah metode deskriptif dengan menggunakan teknik observasi, telaah pustaka, dan wawancara. Instrumen yang digunakan berupa pedoman wawancara, pedoman inventaris, dan kartu data. Sumber data dalam penelitian ini adalah 14 lirik tembang yang diperoleh dari wawancara dan studi pustaka. Dari hasil penelitian ditemukan bahwa tembang Sunda Cigawiran mengalami perkembangan dan struktur puisi yang tentu. Perkembangan tembang Sunda Cigawiran berubah dari waktu ke waktu seiring dengan perkembangan zaman. Struktur lirik tembang Sunda Cigawiran mempunyai struktur fisik (imaji, simbol, musikalitas, dan gaya bahasa) serta struktur batin (tema, rasa, nada, dan amanat). Lirik tembang Sunda Cigawiran secara umum ditulis dalam bentuk pupuh, tapi tidak sepenuhnya memenuhi aturan pupuh yang digunakannya. Téma dari teks tembang Sunda Cigawiran pada umumnya berkaitan erat dengan keagamaan. Imaji yang paling banyak ditemukan dalam teks ini adalah imaji visual (penglihatan). Musikalitas/wirahma tembang Sunda Cigawiran mencakup pada bentuk pupuh, yang mempunyai guru gatra, guru wilangan, dan guru lagu. Gaya bahasa umumnya merupakan bahasa yang umum, hiperbol, dan konotatif. Rasa yang paling banyak ditemukan menunjukkan rasa takut. Sedangkan amanat secara umum adalah memebrikan peringatan kepada manusia agar selamanya memohon perlindungan kepada Alloh swt. Dalam lirik tembang Sunda Cigawiran terkandung nilai etnopedagogik, yaitu Prilaku Nyunda Trisilas (silih asih, silih asah, silih asuh), Catur Jatidiri Insan (pengkuh agamana, jembar budayana, luhung élmuna, rancagé gawéna), Gapura Panca Waluya (cageur, bageur, bener, pinter, singer), dan Moral Kemanusiaan (moral manusia kepada Tuhan, moral manusia kepada diri pribadi, moral manusia kepada manusia, moral manusia kepada alam, moral manusia kepada waktu, dan moral manusia dalam mencapai kepuasan lahir dan batin).
\end{abstract}

Kata kunci: lirik tembang, historis, stuktural, etnopedagogik

\section{THE LYRIC OF CIGAWIRAN SUNDANESE SONG (Historical, Structural, and Etnopedagogic Studies)}

\begin{abstract}
The purpose of this study describes the development, structures, and etnopedagogic values of Cigawiran Sundanese song lyrics. The method used in this research is descriptive method, while the data is taken by observation technique, literature review, and interview. The instruments used are interview guides, inventory guides, and data cards. The data sources in this study are 14 songs lyrics obtained from the interviews and literature study. From the research results found that Cigawiran Sundanese song has developed and formed its structures of poetry. The development of Cigawiran Sundanese song changed from time to time along with the period. Cigawiran Sundanese song structure has the physical structures
\end{abstract}


(images, symbols, musicalities, and language styles) and the inner structures (themes, tastes, tones, and messages). Cigawiran Sundanese song lyrics in generally are written in stanzas, but does not fully comply with the rules of the stanzas it used. The theme of the Cigawiran Sundanese song texts are generally closely related to religion. The most common images found in this text is the visual image (sight). Musicality of Cigawiran Sundanese song includes the stanza form, which has guru gatra, guru wilangan, and guru lagu. Language styles are generally a common language, hyperbole, and connotative. The most common sense shows fear. While the message in generally gives warning that people must always ask protection to Alloh SWT. In the Cigawiran Sundanese song lyrics contained etnopedagogic values. That are Prilaku Nyunda Trisilas (silih asih, silih asah, silih asuh), Catur Jatidiri Insan (pengkuh agamana, jembar budayana, luhung élmuna, rancagé gawéna), Gapura Panca Waluya (cageur, bageur, bener, pinter, singer), and humanity moral (the moral of human to God, the moral of human to themself, the moral of human to other human being, the moral of human to nature, the moral of human to the time, and the moral of human in achieving physical and mental satisfaction).

Keywords: song lyrics, historical, structural, ethnopedagogic

\section{PENDAHULUAN}

Fungsi pendidikan dalam konteks kebudayaan salah satunya adalah untuk mewariskan nilai-nilai kemanusiaan yang bersumber dari budaya lingkungan sekitar. Hal ini lebih dikenal dengan sebutan kearifan lokal. Kearifan lokal (local wisdom) terdiri dari dua kata yaitu kearifan (wisdom) dan lokal (local). Menurut Rusyana dalam Sudaryat (2015, hlm. 123), kearifan lokal adalah kemampuan masyarakat dalam memanfaatkan fasilitas yang diberikan oleh Tuhan kepada manusia. Fasilitas itu berupa alam fisik, alam hayati, komunitas masyarakat beserta norma-normanya, budaya, dan agama. Oleh karena itu, dalam dunia pendidikan saat ini, berlangsungnya proses belajarmengajar diimbuhi oleh unsur kearifan lokal (local wisdom), sebab kearifan lokal bisa dijadikan sumber penting untuk membangun generasi muda yang berkarakter. Salah satunya yaitu melalui tembang Sunda Cigawiran yang merupakan salah satu wujud kearifan budaya lokal Cigawir, Kecamatan Selaawi, Kabupaten Garut.

Tembang Sunda Cigawiran lahir dan berkembang di lingkungan masyarakat Cigawir. Menurut Budiwati (2003, hlm. 5),
Cigawiran mempunya makna, simbol, peranan, fungsi, filsafat, dan unsur seni beserta nilai yang mandiri. Pada waktu itu, tembang Sunda Cigawiran mempunyai fungsi untuk syiar agama Islam, sebab di dalam lirik tembang Sunda Cigawiran umumnya mempunyai fatwa-fatwa yang bersifat ajakan dan pendidikan. Kenyataannya, pada saat ini eksistensi tembang Sunda Cigawiran semakin merosot akibat adanya pengaruh dari budaya asing yang telah menyebar dan mempengaruhi diri para generasi muda (Sunda hususnya).

Untuk mengatasi permasalahan tersebut, peneliti merasa perlu untuk memperkenalkan kembali tembang Sunda Cigawiran dengan cara menggali nilai-nilai yang terkandung dalam lirik tembang Sunda Cigawiran, yaitu nilai etnopedagogik lirik Tembang Sunda Cigawiran.

\section{METODE}

Menurut Siswantoro (2014, hlm. 5556), metode adalah cara yang digunakan oleh peneliti untuk menyelesaikan masalah yang diteliti. Metode penelitian adalah cara ilmiah untuk memperoleh data dan tujuan beserta fungsi yang tentu (Sugiyono, 2013, hlm. 2). Metode yang digunakan dalam penelitian ini adalah metode deskriptif. 
Metode deskriptif adalah metode yang digunakan untuk menyelesaikan masalah yang diteliti dengan cara menggambarkan keadaan subjek atau objek penelitian (novel, drama, cerita pendek, puisi) berdasarkan fakta yang ada di lapangan (Nawawi dalam Siswantoro, 2014, hlm.
56). Data dalam penelitian ini adalah buku kumpulan Tembang Pasantren Hariring Dangding Cigawiran, dengan informannya adalah ahli seni tembang Sunda Cigawiran yang bernama R. Iyet Dimyati. Di bawah ini disajikan sumber data penelitian.

\section{Tabel 1: Sumber Data}

\begin{tabular}{|c|c|c|c|}
\hline No. & Judul RTSC & Pengarang & Sumber Data \\
\hline 1. & Muqoddimah & R. Iyét Dimyati & $\begin{array}{c}\text { Buku "Tembang Pasantrén Hariring } \\
\text { Dangding Cigawiran" }\end{array}$ \\
\hline 2. & Gandrungan & R. Iyét Dimyati & $\begin{array}{c}\text { Buku "Tembang Pasantrén Hariring } \\
\text { Dangding Cigawiran" }\end{array}$ \\
\hline 3. & Kaluar Nyawa & R. Iyét Dimyati & $\begin{array}{c}\text { Buku "Tembang Pasantrén Hariring } \\
\text { Dangding Cigawiran" }\end{array}$ \\
\hline 4. & Ahli Mayit (Kinanti) & R. Iyét Dimyati & $\begin{array}{c}\text { Buku "Tembang Pasantrén Hariring } \\
\text { Dangding Cigawiran" }\end{array}$ \\
\hline 5. & Siksaan Kubur & R. Iyét Dimyati & $\begin{array}{c}\text { Buku "Tembang Pasantrén Hariring } \\
\text { Dangding Cigawiran" }\end{array}$ \\
\hline 6. & Sinom & R. Iyét Dimyati & $\begin{array}{c}\text { Buku "Tembang Pasantrén Hariring } \\
\text { Dangding Cigawiran" }\end{array}$ \\
\hline 7. & Pangkat (Sinom) & R. Iyét Dimyati & $\begin{array}{c}\text { Buku "Tembang Pasantrén Hariring } \\
\text { Dangding Cigawiran" }\end{array}$ \\
\hline 8. & Patrol & R. Iyét Dimyati & $\begin{array}{c}\text { Buku "Tembang Pasantrén Hariring } \\
\text { Dangding Cigawiran" }\end{array}$ \\
\hline 9. & Daqo'iqul Akhbar & R. Iyét Dimyati & $\begin{array}{c}\text { Buku "Tembang Pasantrén Hariring } \\
\text { Dangding Cigawiran" }\end{array}$ \\
\hline 10. & Bubuka & R. Iyét Dimyati/ Aang Hidayat & Wawancara \\
\hline & Poé Qiyamat (Durma) & R. Iyét Dimyati/ Aang Hidayat & Wawancara \\
\hline & Alam Mahsar (Sinom) & R. Iyét Dimyati/ Aang Hidayat & Wawancara \\
\hline 13. & Liwung & R. Iyét Dimyati/ Aang Hidayat & Wawancara \\
\hline & Sakatén & R. Iyét Dimyati/ Aang Hidayat & Wawancara \\
\hline
\end{tabular}

\section{HASIL DAN PEMBAHASAN} Kamekaran Tembang Sunda Cigawiran

Cigawiran lahir pada tahun 1713 yang dipelopori oleh R. H. Muhammad Djalari yang menjabat sebagai pemimpin di Pesantren Cigawir. R. H. Muhammad Djalari terkenal sebagai tokoh agama Islam yang taat kepada ajaran dan aturan-aturan agama Islam. Selain itu, R. H. Muhammad Djalari juga mempunyai bakat dalam bidang seni.

Kesenian tembang Sunda Cigawiran merupakan kesenian yang sifatnya turuntemurun. Maka dari itu, R. H. Muhammada Djalari mewariskan tembang Sunda Cigawiran kepada para putranya, yaitu $\mathrm{R}$. H. Abdullah Usman, R. Memed, R. Idik,
R. H. Ibrohim, R. Muhammad Isya (turun kepada putranya, yaitu R. Agus Gaos, R. Iyet Dimyati Mamun, serta $\mathrm{Ki}$ Amin Ciputat), dan R. Siti Rohmah. Kesenian ini, ditransformasikan juga kepada muridmuridnya yang menjadi santri dipesantrennya.

Agar mempunya ciri khas, maka guguritan yang digurit oleh $\mathrm{R}$. $\mathrm{H}$. Muhammad Djalari diberi nama Cigawiran. Menurut beliau, kesenian ini merupakan salah satu karya seni yang ditampilkan untuk masyarakat dengan ciri khasnya sendiri, serta Cigawir merupakan nama tempat yang menjadi inspirasi untuk beliau di dalam menciptakan karya seni. 
Kesenian tembang Sunda Cihawiran yang lahir dan berkembang di lingkungan Pesantren Cigawir, mengalami perubahan dan perkembangan dari waktu ke waktu. Pada waktu kepemimpinan R. H. Abdullah Usman, Cigawiran mengalami kemajuan yang begitu pesat. Hal ini dibuktikan dengan banyaknya masyarakat yang ingin belajar menembangkan tembang Sunda Cigawiran. Selain itu, lirik tembangnya semakin bertambah. Beliau cukup aktif dan kreatif dalam menciptakan lirik tembang Sunda Cigawiran yang berdasarkan pada pola lirik yang sudah ada. Suara yang merdu menjadi nilai tambah untuk menembangkan tembang Sunda Cigawiran. Masyarakat banyak yang tertarik oleh merdunya suara R. H. Abdullah Usman.

Tahun 1950-an, kesenian tembang Sunda Cigawiran sering ditampilkan (di lingkungan masyarakat Cigawir khususnya) dalam acara kegiatan upacara adat, seperti: pernikahan, khitanan, dan juga dalam situasi berkabung (yang oleh masyarakat Cigawir disebut sawer mayit atau sawer kubur), serta dalam kegiatan lainnya.

Pada tahun 1976, kesenian tembang Sunda Cigawiran pernah ditampilkan oleh R. Agus Gaos, R. Iyet Dimyati, dan Ki Moh. Amin di Gedung Merdeka yang dihadiri oleh Gubernur Aang Kunaepi, kemudian di Hotel Savoy Homan yang dihadiri oleh Gubernur R. Nuryana. Sejak saat itu, kesenian tembang Sunda Cigawiran mulai dikenal dan diakui oleh masyarakat luar (terutama oleh komunitas seni).

Sejak tahun 1980-an, perkembangan kesenian tembang Sunda Cigawiran tidak mengalami perubahan yang signifikan, walaupun kesenian tembang Sunda Cigawiran masih ditampilkan dalam beberapa kegiatan.

Pada era kepemimpinan $\mathrm{R}$. Iyet Dimyati, beliau ngagurit lirik tembang Sunda Cigawiran disesuaikan dengan maksud serta tujuan yang memerlukan, contohna dalam kegiatan serah terima pengantin, lamaran, menerima tamu kehormatan, dan sebagainya. Selain itu, R. Iyet Dimyati juga sering didatangi oleh mahasiswa dan para ahli seni budaya (dosen) untuk memperoleh ilmu pengetahuan tentang kesenian tembang Sunda Cigawiran. Seiring dengan berjalannya waktu, kesenian tembang Sunda Cigawiran mulai dimasukkan ke dalam kurikulum di STSI Bandung. Tahun 2010, Gubernur Jawa Barat (Bapak H. Heryawan) membuktikan dan memberikan sumbangsih sebagai rasa cintanya terhadap seni budaya di tatar Sunda dengan mendirikan Padepokan Cigawiran. Saat ini, hanya tinggal $\mathrm{R}$. Iyet Dimyati-lah yang menjadi sesepuh kesenian tembang Sunda Cigawiran.

Pada awalnya, tujuan diciptakannya kesenian tembang Sunda Cigawiran adalah sebagai alat atau media untuk menyebarkan agama Islam, sebab pada waktu itu kegiatan tersebut sangatlah dilarang oleh kaum penjajah. Dengan adanya kesenian ini, kegiatan menyebarkan agama Islam bisa tetap berjalan karena kaum penjajah tidak mengetahui bahwa di dalam Cigawiran mengandung nilai-nilai keagamaan.

Setelah diteliti, ternyata fungsi awal yang diterima oleh masyarakat Cigawir adalah fungsi hiburan. Keadaan masyarakat pada waktu itu merasa cukup terhibur dengan adanya Cigawiran, walaupun tidak memahami dan mengetahui tentang isi dari kesenian tersebut yang memiliki nilai-nilai keagamaan yang bersumber dari Al-Qur'an dan Al-Hadits. Masyarakat merasa tertarik oleh seni Cigawiran, sehingga setiap kali Cigawiran ditampilkan masyarakat selalu datang untuk menyaksikannya. Keadaan ini menjadi sebuah keuntungan untuk para ulama dalam menyebarkan agama Islam, sebab para ulama tidak perlu susah payah mencari cara untuk mengumpulkan masyarakat yang menjadi jemaatnya. 
Berdasarkan hasil temuan di lapangan, kesenian Cigawiran mempunyai fungsi utama seperti di bawah ini.

1) Fungsi réligius, yaitu sebagau wujud dari diterapkannya ajaran agama Islam. Cigawiran dijadikan média dalam menyampaikan ajaran yang berasal dari norma-norma agama Islam, fatwafatwa, ajakan-ajakan, pendidikan, yang bersumber dari Al-Qur'an dan AlHadits.

2) Fungsi untuk media upacara adat, seperti dalam serah terima pengantin laki-laki dan perempuan, buka pintu, sawer pengantin, dan sawer khitanan serta sawer kubur atau "talqin". Hal ini diharapkan bisa menerapkan nilai-nilai tradisi dan budaya kehidupan masyarakat Cigawir.

3) Fungsi sosial, sebagai wujud dalam menerapkan nilai kemasyarakatan yaitu tata cara yang mengatur kehidupan dan melakukan pola tingkah laku manusia sesuai dengan falsafah serta tujuan hidupnya, bahwa manusia hidup di tengah-tengah masyarakat dan lingkungannya.

4) Fungsi seni, sebagai wujud dalam menerapkan nilai estetis, nilai keindahan artistik. Hal ini dianggap perlu sebab dalam kehidupan manusia senantiasa memerlukan satu hal yang bersifat memuaskan dan memerlukan hal-hal yang berkaitan dengan kaindahan estetis serta artistik. Selain itu, manusia memerlukan média untuk mengungkapkan rasa yang ada dalam hatinya (emosi dan kreasi).

5) Fungsi hiburan, hal ini bertujuan untuk menghibur diri, mencari kepuasan, dan menghilangkan rasa bosan setelah melakukan rutinitas sehari-hari, baik untuk dirinya sendiri ataupun untuk masyarakat lain.

\section{Struktur Lirik Tembang Sunda Cigawiran \\ Struktur lirik tembang Sunda} Cigawiran meliputi struktur fisik dan struktur batin. Struktur fisik meliputi imaji, simbol, musiklaitas/wirahma (guru gatra, guru wilangan, dan guru lagu), serta gaya bahasa. Struktur batin meliputi tema, rasa, nada, dan amanat.

\section{Struktur Fisik Lirik Tembang Sunda Cigawiran}

Berdasarkan hasil penelitian, lirik tembang Sunda Cigawiran yang dibahas berjumlah empat belas tembang. Setiap lirik mempunyai wirahma/musikalitas (guru gatra, guru wilangan, dan guru lagu) yang berbeda. Supaya lebih terlihat perbedaannya, di bawah ini dijelaskan tentang wirahma/musikalitas (guru gatra, guru wilangan, dan guru lagu) dari lirik tembang Sunda Cigawiran.

Tabel 2:

Wirahma (Guru Gatra, Guru Wilangan, Guru Lagu, dan Bentuk Pupuh)

\begin{tabular}{|c|c|c|c|c|c|c|}
\hline \multirow{2}{*}{$\begin{array}{c}\text { No. } \\
1 .\end{array}$} & \multirow{2}{*}{\begin{tabular}{|l} 
Judul RTSC \\
Muqoddimah
\end{tabular}} & \multirow{2}{*}{$\begin{array}{c}\text { Jumlah } \\
\text { Gatra }\end{array}$} & \multirow{2}{*}{$\begin{array}{c}\text { Guru } \\
\text { Gatra }\end{array}$} & \multicolumn{2}{|c|}{ Guru Lagu dan Guru Wilangan } & \multirow{2}{*}{\begin{tabular}{l}
\multicolumn{1}{c}{\begin{tabular}{c}
\multicolumn{1}{c}{ Bentuk } \\
Pupuh
\end{tabular}} \\
Dangdanggula \\
Sinom
\end{tabular}} \\
\hline & & & & 1 & $\begin{array}{l}\text { 10-i, 10-a, 8-o, 7-u, 9-i, 8-a, 6-u, } \\
4-u, 16-i, 8-a\end{array}$ & \\
\hline & & & 10 & 2 & $\begin{array}{l}10-i, 10-a, 8-o, 8-u, 8-i, 8-a, 6-u, \\
8-a, 12-i, 7-a\end{array}$ & \\
\hline & & & 10 & 3 & $\begin{array}{l}10-i, 10-a, 8-o, 8-u, 8-i, 8-a, 6-u, \\
8-a, 12-i, 8-a\end{array}$ & \\
\hline & & & 10 & 4 & $\begin{array}{l}\text { 10-i, 10-a, 8-é, 8-u, 8-i, 8-a, 6-u, } \\
\text { 8-a, 12-i, 8-a }\end{array}$ & \\
\hline & & & 10 & 5 & $\begin{array}{l}\text { 10-i, 10-a, 8-é, 8-u, 8-i, 8-a, 6-u, } \\
9 \text {-a, 12-i, 8-a }\end{array}$ & \\
\hline & & & 9 & $6 \& 8$ & 8-a, 8-i, 8-a, 8-i, 8-i, 8-u, 8-a, 8-i, & \\
\hline
\end{tabular}




\begin{tabular}{|c|c|c|c|c|c|c|}
\hline \multirow[t]{5}{*}{ No. } & \multirow[t]{5}{*}{ Judul RTSC } & \multirow[t]{5}{*}{$\begin{array}{l}\text { Jumlah } \\
\text { Gatra }\end{array}$} & \multirow{3}{*}{$\begin{array}{c}\begin{array}{c}\text { Guru } \\
\text { Gatra }\end{array} \\
9 \\
\end{array}$} & \multicolumn{2}{|r|}{ Guru Lagu dan Guru Wilangan } & \multirow[t]{2}{*}{$\begin{array}{l}\text { Bentuk } \\
\text { Pupuh }\end{array}$} \\
\hline & & & & & $12-\mathrm{a}$ & \\
\hline & & & & 7 & $\begin{array}{l}\text { 8-a, 8-i, 8-a, 8-i, 7-i, 8-u, 8-a, 8-i, } \\
12-a\end{array}$ & \\
\hline & & & 10 & 9 & $\begin{array}{l}\text { 10-i, 8-a, 8-é, 8-u, 8-i, 8-a, 6-u, 8- } \\
\text { a, 12-i, 8-a }\end{array}$ & \\
\hline & & & 10 & 10 & $\begin{array}{l}\text { 10-i, 8-a, 8-é, 8-u, 8-i, 8-a, 6-u, 7- } \\
a, 12-i, 8-a\end{array}$ & \\
\hline \multirow[t]{6}{*}{2.} & Gandrungan & 6 & 10 & 1 & $\begin{array}{l}\text { 10-i, 10-a, 8-o, 7-u, 9-i, 8-a, 6-u, } \\
8-a, 12-i, 11-a\end{array}$ & Dangdanggula \\
\hline & & & & 2 & $\begin{array}{l}\text { 10-i, 10-a, 8-é, 8-u, 8-i, 8-a, 6-u, } \\
\text { 8-a, 11-i, 8-a }\end{array}$ & \\
\hline & & & & 3 & $\begin{array}{l}\text { 10-i, 10-a, 8-é, 7-u, 10-i, 8-a, 6-u, } \\
\text { 8-a, 12-i, 8-a }\end{array}$ & \\
\hline & & & & 4 & $\begin{array}{l}\text { 10-i, 11-a, 8-o, 7-u, 9-i, 8-a, 6-u, } \\
\text { 8-a, 12-i, 8-a }\end{array}$ & \\
\hline & & & & 5 & $\begin{array}{l}\text { 10-i, 10-a, 8-o, 7-u, 8-i, 8-a, 6-u, } \\
8-a, 12-i, 8-a\end{array}$ & \\
\hline & & & & 6 & $\begin{array}{l}\text { 10-i, 10-a, 8-é, 7-u, 10-i, 8-a, 6-u, } \\
\text { 8-a, 11-i, 8-a }\end{array}$ & \\
\hline \multirow[t]{8}{*}{3.} & Kaluar Nyawa & 8 & 10 & 1 & $\begin{array}{l}\text { 10-i, 10-a, 8-o, 8-u, 9-i, 8-a, 6-u, } \\
8-a, 12-i, 8-a\end{array}$ & Dangdanggula \\
\hline & & & 10 & 2 & $\begin{array}{l}\text { 10-i, 10-a, 8-o, 8-u, 10-i, 8-a, 6-u, } \\
\text { 8-a, 12-i, 7-a }\end{array}$ & \\
\hline & & & 10 & 3 & $\begin{array}{l}\text { 10-i, 10-a, 8-o, 7-u, 10-i, 8-a, 6-u, } \\
\text { 8-a, 12-i, 7-a }\end{array}$ & \\
\hline & & & 10 & 4 & $\begin{array}{l}\text { 10-i, 10-a, 8-o, 7-u, 10-i, 8-a, 6-u, } \\
9-a, 12-i, 7-a\end{array}$ & \\
\hline & & & 10 & 5 & $\begin{array}{l}\text { 9-i, 10-a, 8-o, 6-u, 8-i, 7-a, 6-u, 8- } \\
a, 12-i, 7-a\end{array}$ & \\
\hline & & & 10 & 6 & $\begin{array}{l}\text { 10-i, 10-a, 8-é, 7-u, 10-i, 8-a, 6-u, } \\
13-a, 11-i, 7-a\end{array}$ & \\
\hline & & & 10 & 7 & $\begin{array}{l}\text { 10-i, 10-a, 8-é, 8-u, 9-i, 8-a, 6-u, } \\
\text { 8-a, 11-i, 8-a }\end{array}$ & \\
\hline & & & 10 & 8 & $\begin{array}{l}\text { 9-i, 10-a, 8-o, 8-u, 8-i, 7-a, 6-u, 8- } \\
\text { a, 11-i, 7-a }\end{array}$ & \\
\hline \multirow[t]{2}{*}{4.} & $\begin{array}{l}\text { Ahli Mayit } \\
\text { (Kinanti) }\end{array}$ & 13 & 6 & $\begin{array}{c}1-9,11- \\
13\end{array}$ & $8-u, 8-i, 8-a, 8-i, 8-a, 8-i$ & Kinanti \\
\hline & & & 6 & 10 & 8-u, 8-i, 8-a, 7-i, 8-a, 8-i & \\
\hline 5. & Siksaan Kubur & 11 & 6 & $1-11$ & $8-u, 8-i, 8-a, 8-i, 8-a, 8-i$ & Kinanti \\
\hline \multirow[t]{2}{*}{6.} & Sinom & 6 & 9 & $1,2,5$ & $\begin{array}{l}\text { 8-a, 8-i, 8-a, 8-i, 7-i, 8-u, 8-a, 8-i, } \\
12-a\end{array}$ & Sinom \\
\hline & & & 9 & $3,4,6$ & $\begin{array}{l}\text { 8-a, 8-i, 8-a, 8-i, 8-i, 8-u, 8-a, 8-i, } \\
12-a\end{array}$ & \\
\hline \multirow[t]{3}{*}{7.} & $\begin{array}{l}\text { Pangkat } \\
\text { (Sinom) }\end{array}$ & 3 & 9 & 1 & $\begin{array}{l}\text { 8-a, 8-i, 8-a, 8-i, 7-i, 8-u, 8-a, 8-i, } \\
12-a\end{array}$ & Sinom \\
\hline & & & 9 & 2 & $\begin{array}{l}\text { 8-a, 7-i, 8-a, 8-i, 8-i, 8-u, 7-a, 8-i, } \\
12-a\end{array}$ & \\
\hline & & & 9 & 3 & $\begin{array}{l}\text { 8-a, 8-i, 8-a, 8-i, 7-i, 8-u, 7-a, 8-i, } \\
12-a\end{array}$ & \\
\hline & Patrol & 4 & 9 & 1 & $\begin{array}{l}\text { 11-i, 10-a, 8-o, 8-u, 8-i, 8-a, 6-u, } \\
20-i, 8-a\end{array}$ & Sinom \\
\hline & & & 9 & 2 & $\begin{array}{l}\text { 10-i, 10-a, 8-é, 8-u, 7-i, 6-a, 6-u, } \\
20-i, 8-a\end{array}$ & \\
\hline & & & 9 & 3 & $\begin{array}{l}\text { 10-i, 12-a, 8-é, 8-u, 8-i, 8-a, 6-u, } \\
\text { 20-i, 8-a }\end{array}$ & \\
\hline
\end{tabular}




\begin{tabular}{|c|c|c|c|c|c|c|}
\hline \multirow[t]{2}{*}{ No. } & \multirow[t]{2}{*}{ Judul RTSC } & \multirow[t]{2}{*}{$\begin{array}{c}\text { Jumlah } \\
\text { Gatra }\end{array}$} & \multirow{2}{*}{$\begin{array}{c}\begin{array}{c}\text { Guru } \\
\text { Gatra }\end{array} \\
9\end{array}$} & \multicolumn{2}{|r|}{ Guru Lagu dan Guru Wilangan } & \multirow{2}{*}{$\begin{array}{l}\text { Bentuk } \\
\text { Pupuh }\end{array}$} \\
\hline & & & & 4 & $\begin{array}{l}\text { 10-i, 10-a, 8-o,7-u, 8-i, 7-a, 6-u, } \\
\text { 20-a, 8-a }\end{array}$ & \\
\hline \multirow[t]{3}{*}{9.} & $\begin{array}{l}\text { Daqo'iqul } \\
\text { Akhbar }\end{array}$ & 5 & 9 & $1 \& 4$ & $\begin{array}{l}\text { 8-a, 8-i, 8-a, 8-i, 7-i, 8-u, 8-a, 8-i, } \\
12-a\end{array}$ & Sinom \\
\hline & & & 9 & $2 \& 5$ & $\begin{array}{l}\text { 8-a, 8-i, 8-a, 8-i, 8-i, 8-u, 8-a, 8-i, } \\
12-a\end{array}$ & \\
\hline & & & 9 & 3 & $\begin{array}{l}\text { 8-a, 8-i, 8-a, 8-i, 8-i, 8-u, 7-a, 8-i, } \\
12-a\end{array}$ & \\
\hline \multirow[t]{3}{*}{10.} & Bubuka & 3 & 9 & 1 & $\begin{array}{l}\text { 9-i, 10-a, 8-o, 7-u, 9-i, 13-u, 4-u, } \\
10-a, 14-a\end{array}$ & $\begin{array}{l}\text { Dangdanggula } \\
\text { Sinom }\end{array}$ \\
\hline & & & 9 & 2 & $\begin{array}{l}\text { 8-a, 8-i, 8-a, 8-i, 7-i, 8-u, 8-a, 8-i, } \\
13-a\end{array}$ & \\
\hline & & & 10 & 3 & $\begin{array}{l}\text { 8-a, 8-i, 8-a, 8-i, 8-i, 8-u, 8-a, 8-i, } \\
\text { 8-u, 9-a }\end{array}$ & \\
\hline \multirow[t]{9}{*}{11.} & $\begin{array}{l}\text { Poé Qiyamat } \\
\text { (Durma) }\end{array}$ & 14 & 7 & 1 & 11-a, 8-i, 8-a, 8-a, 8-a, 7-a, 8-i & Durma \\
\hline & & & 7 & $2,3,14$ & 12-a, 8-i, 8-a, 8-a, 8-i, 6-a, 8-i & \\
\hline & & & 7 & $4,6,7,11$ & $12-a, 8-i, 8-a, 8-a, 8-i, 7-a, 8-i$ & \\
\hline & & & 7 & 5 & 12-a, 8-i, 9-a, 8-a, 8-i, 7-a, 8-i & \\
\hline & & & 7 & 8 & $12-a, 8-i, 8-a, 7-a, 8-i, 6-a, 8-i$ & \\
\hline & & & 7 & 9 & 12-a, 8-i, 8-a, 8-a, 8-i, 8-a, 8-i & \\
\hline & & & 7 & 10 & 12-a, 8-i, 8-a, 8-a, 8-i, 5-a, 8-i & \\
\hline & & & 7 & 12 & 12-a, 7-i, 8-a, 8-a, 8-i, 6-a, 8-i & \\
\hline & & & 7 & 13 & 10-a, 8-i, 8-a, 7-a, 8-é, 6-o, 8-i & \\
\hline \multirow[t]{12}{*}{12.} & $\begin{array}{l}\text { Alam Mahsar } \\
\text { (Sinom) }\end{array}$ & 20 & 9 & $\begin{array}{c}1,5,11 \\
13,15\end{array}$ & $\begin{array}{l}\text { 8-a, 8-i, 8-a, 8-i, 8-i, 8-u, 7-a, 8-i, } \\
12-a\end{array}$ & Sinom \\
\hline & & & 9 & 2 & $\begin{array}{l}\text { 8-a, 8-i, 8-a, 8-i, 7-i, 8-u, 7-a, 8-i, } \\
12-a\end{array}$ & \\
\hline & & & 10 & 3 & $\begin{array}{l}\text { 8-a, 8-i, 8-a, 8-i, 8-i, 8-u, 7-a, 8-i, } \\
\text { 4-u, 8-a }\end{array}$ & \\
\hline & & & 10 & 4 & $\begin{array}{l}\text { 8-a, 8-i, 8-a, 8-i, 8-i, 8-u, 8-a, 8-i, } \\
\text { 4-u, 8-a }\end{array}$ & \\
\hline & & & 10 & 6 & $\begin{array}{l}\text { 8-a, 8-i, 8-a, 8-i, 8-i, 8-u, 8-a, 8-i, } \\
\text { 4-a, 8-a }\end{array}$ & \\
\hline & & & 10 & 7 & $\begin{array}{l}\text { 8-a, 8-i, 6-a, 8-i, 8-i, 8-u, 7-a, 8-i, } \\
\text { 4-a, 8-a }\end{array}$ & \\
\hline & & & 10 & 8 & $\begin{array}{l}\text { 8-a, 8-i, 8-a, 8-i, 7-i, 8-u, 8-é, 8-i, } \\
\text { 4-a, 8-a }\end{array}$ & \\
\hline & & & 10 & 9 & $\begin{array}{l}\text { 8-a, 8-i, 8-a, 8-i, 7-i, 8-u, 8-a, 8-i, } \\
8-u, 4-a\end{array}$ & \\
\hline & & & 10 & 10 & $\begin{array}{l}\text { 8-a, 8-i, 8-a, 8-i, 8-i, 7-u, 7-a, 8-i, } \\
\text { 6-a, 6-a }\end{array}$ & \\
\hline & & & 9 & $\begin{array}{l}12,16 \\
17,19\end{array}$ & $\begin{array}{l}\text { 8-a, 8-i, 8-a, 8-i, 8-i, 8-u, 8-a, 8-i, } \\
12-a\end{array}$ & \\
\hline & & & 9 & 18 & $\begin{array}{l}\text { 8-a, 8-i, 8-a, 8-i, 8-i, 9-u, 8-a, 8-i, } \\
12-a\end{array}$ & \\
\hline & & & 4 & 20 & $8-u, 13-i, 8-a, 8-i$ & \\
\hline 13. & Liwung & 1 & 9 & 1 & $\begin{array}{l}\text { 8-a, 8-i, 8-a, 8-i, 8-i, 8-u, 8-a, 8-i, } \\
12-a\end{array}$ & Sinom \\
\hline 14. & Sakatén & 1 & 9 & 1 & $\begin{array}{l}\text { 8-a, 8-i, 8-a, 8-i, 8-i, 8-u, 8-a, 8-i, } \\
12-a\end{array}$ & Sinom \\
\hline
\end{tabular}

Berdasarkan tabel di atas, bisa terlihat bahwa dari 14 tembang yang dianalisis semuanya ditulis dalam bentuk pupuh, tapi tidak sesuai dengan aturan 
pupuh yang digunakannya sebab ada kesalahan dalam guru gatra, guru wilangan, dan guru lagunya. Jumlah lirik yang sesuai dengan aturan pupuhnya hanya ada satu, sedangkan jumlah lirik yang tidak sesuai dengan aturan pupuh ada 13 .

Lirik yang sesuai dengan aturan pupuh adalah lirik "Siksaan Kubur", sedangkan lirik yang tidak sesuai dengan patokan pupuh adalah lirik "Muqoddimah", "Gandrungan", "Kaluar Nyawa", "Ahli Mayit (Kinanti)", "Sinom", "Pangkat (Sinom)", "Patrol", "Daqo'iqul Akhbar", "Bubuka", "Poé Qiyamat (Durma)", "Alam Mahsar (Sinom)", "Liwung", dan "Sakatén".

Dalam lirik "Muqoddimah" terdapat kesalahan pada guru wilangan dan guru lagu, lirik "Gandrungan" terdapat kesalahan pada guru gatra dan guru wilangan, rumpaka "Kaluar Nyawa" terdapat kesalahan pada guru wilangan dan guru lagu. Kemudian lirik "Ahli Mayit (Kinanti) terdapat kesalahan pada guru wilangan, lirik "Sinom" dan "Pangkat (Sinom)" terdapat kesalahan pada guru wilangan. Lirik "Patrol" terdapat kesalahan pada guru gatra, guru wilangan, dan guru lagu. Lirik "Daqo'iqul Akhbar" terdapat kesalahan pada guru wilangan, sedangkan lirik "Bubuka" kesalahnnya terletak pada guru gatra, guru wilangan, dan guru lagu. Lirik "Poé Qiyamat (Durma)" terdapat kesalahan pada guru lagu dan guru wilangan, berbeda dengan lirik "Alam Mahsar" yang kesalahannya terletak pada guru gatra, guru wilangan, dan guru lagu. Kemudian lirik "Liwung" dan lirik "Sakatén" terdapat kesalahan pada guru wilangannya.

Adanya hal-hal yang tidak sesuai dengan aturan pupuh pada lirik tembang Sunda Cigawiran disebabkan oleh kurangnya pengetahuan dari pengarang terhadap bidang sastra, khususnya mengenai tembang, sebab pendidikan pengarang hanya sampai pada Sekolah Rakyat.
Oleh karena itu, bisa disimpulkan bahwa lirik tembang Sunda Cigawiran ditulis dalam bentuk pupuh, tapi tidak sesuai dengan patokan pupuh yang digunakan karena terdapat beberapa kesalahan dalam hal guru gatra, guru wilangan, dan guru lagunya.

\section{Imaji}

Imaji yang terdapat pada lirik tembang Sunda Cigawiran meliputi imaji visual (penglihatan), imaji auditif (pendengaran), dan imaji taktil (rasa). Secara umum, imaji yang paling banyak ditemukan dalam lirik tembang Sunda Cigawiran adalah imaji visual (penglihatan), karena dalam lirik tembang Sunda Cigawiran banyak terkandung petuah yang diperlihatkan melalui penglihatan.

\section{Simbol}

Kata-kata yang banyak digunakan sebagai simbol/lambang dalam lirik tembang Sunda Cigawiran adalah kata yang menggambarkan atau menyimbolkan hal yang berhubungan dengan keagamaan, seperti kata Gusti, Alhamdulillah, Pangéran, Gusti Yang Manon, dho'if, dan sebagainya. Hal tersebut disebabkan oleh isi dari lirik tembang Sunda Cigawiran yang erat hubungannya dengan keagamaan, sebab fungsi tembang Sunda Cigawiran salah satunya adalah sebagai media da'wah untuk menyebarkan agama Islam.

\section{Gaya Bahasa}

Secara umum, gaya bahasa yang terdapat dalam lirik tembang Sunda Cigawiran menggunakan bahasa yang umum, hiperbola, dan konotatif. Gaya bahasa yang umum digunakan agar pembaca mudah mengerti dan memahami terhadap isi cerita yang terkandung dalam lirik. Gaya bahasa hiperbol digunakan untuk menguatkan cerita, agar pembaca merasa tertarik dan yakin terhadap cerita 
yang digambarkan dalam isi lirik. Gaya bahasa konotatif digunakan untuk membangkitkan rasa penasaran pembaca, sebab untuk memahami isi lirik yang mengandung gaya bahasa konotatif pembaca harus beberapa kali membaca terhadap lirik dari tembang tersebut. Oleh karena itu, bisa disimpulkan gaya bahasa yang digunakan dalam lirik tembang Sunda Cigawiran variatif dan tidak monoton.

\section{Struktur Batin Lirik Tembang Sunda Cigawiran}

Berdasarkan hasil analisis, lirik tembang Sunda Cigawiran secara umum mempunyai tema yang berkaitan dengan keagamaan. Hal ini dapat terlihat dari lirik "Muqoddimah", "Gandrungan", "Kaluar Nyawa", "Ahli Mayit (Kinanti)", "Siksaan Kubur", "Sinom", "Pangkat (Sinom)", "Patrol", "Daqo'iqul Akhbar", "Bubuka", "Poé Qiyamat(Durma)", "Alam Mahsar (Sinom)", dan "Liwung", sedangkan lirik "Sakatén" mempunyai tema tentang kebahagiaan dan ketentraman hidup.

Rasa yang paling banyak terdapat dalam lirik tembang Sunda Cigawiran adalah rasa takut sebab lirik ini banyak menceritakan tentang siksaan di akhirat untuk manusia yang melakukan dosa kepada Tuhan. Rasa yang lainnya adalah rasa sedih, bingung, menyesal, bahagia, saling menyayangi, rendah hati, harapan, marah, percaya diri, dan tentram.

\section{Nilai Etnopedagogik Lirik Tembang Sunda Cigawiran}

Lirik tembang Sunda Cigawiran mempunyai nilai etnopedagogik yang sangat tinggi, seperti yang ditemukan pada hasil analisis. Nilai etnopedagogik yang terkandung dalam lirik tembang Sunda Cigawiran dijelaskan seperti di bawah ini.

A. Prilaku Nyunda Trisilas

1) Silih Asih: ditunjukkan oleh lirik "Muqoddimah", "Gandrungan",
"Sinom", "Bubuka", dan "Alam Mahsar (Sinom)".

2) Silih Asah: ditunjukkan oleh lirik "Muqoddimah", "Gandrungan", "Ahli Mayit (Kinanti)", "Siksaan Kubur", "Sinom", "Patrol", "Daqo'iqul Akhbar", "Poé Qiyamat (Durma)", dan "Alam Mahsar (Sinom)".

3) Silih Asuh: ditunjukkan oleh lirik "Muqoddimah", "Gandrungan", "Sinom", "Bubuka", "Poé Qiyamat (Durma)", "Alam Mahsar(Sinom)", dan "Liwung".

B. Catur Jatidiri Insan

1) Pengkuh Agamana: ditunjukkan oleh lirik "Muqoddimah", "Gandrungan", "Kaluar Nyawa", "Ahli Mayit (Kinanti)", "Bubuka", "Poé Qiyamat (Durma)", dan "Alam Mahsar (Sinom)".

2) Luhung Élmuna: ditunjukkan oleh lirik "Liwung".

3) Jembar Budayana: ditunjukkan oleh lirik "Muqoddimah".

4) Rancagé Gawéna: ditunjukkan oleh lirik "Muqoddimah", "Liwung", dan "Sakatén".

C. Gapura Panca Waluya

1) Cageur: ditunjukkan oleh lirik "Muqoddimah" dan "Gandrungan".

2) Bageur: ditunjukkan oleh lirik "Muqoddimah", "Gandrungan", "Sinom", "Bubuka", dan "Alam Mahsar (Sinom)".

3) Bener: ditunjukkan oleh lirik "Muqoddimah", "Gandrungan", dan "Alam Mahsar (Sinom)".

4) Pinter: ditunjukkan oleh lirik "Muqoddimah", "Gandrungan", "Sinom", "Bubuka", dan "Liwung".

5) Singer: ditunjukkan oleh lirik "Liwung".

D. Moral Kemanusiaan

1) Moral Manusia terhadap Tuhan: ditunjukkan oleh lirik "Muqoddimah", 
"Gandrungan", "Kaluar Nyawa", "Ahli Mayit (Kinanti)", "Bubuka", "Poé Qiyamat (Durma)", dan "Alam Mahsar (Sinom)".

2) Moral Manusia terhadap Dirinya: ditunjukkan oleh lirik "Muqoddimah", "Gandrungan", "Ahli Mayit (Kinanti)", dan "Alam Mahsar (Sinom)".

3) Moral Manusia terhadap Manusia: ditunjukkan oleh lirik "Muqoddimah" dan "Gandrungan".

4) Moral Manusia terhadap Alam: ditunjukkan oleh lirik "Sakatén".

5) Moral Manusia terhadap Waktu: ditunjukkan oleh lirik "Gandrungan", "Pangkat (Sinom)", dan "Alam Mahsar (Sinom)".

6) Moral Manusia dalam Mencapai Kebahagiaan Lahiriah dan Batiniah: ditunjukkan oleh lirik "Gandrungan", "Sinom", "Bubuka”, jeung "Liwung".

\section{SIMPULAN}

Dari hasil penelitian dapat disimpulkan bahwa (1) perkembangan tembang Sunda Cigawiran mengalami perubahan dari waktu ke waktu, dari generasi ke generasi sesuai dengan perkembangan zaman. (2) Lirik tembang Sunda Cigawiran secara umum ditulis dalam bentuk pupuh, tetapi tidak sesuai dengan aturan pupuh yang digunakan. Imaji yang paling banyak digunakan adalah imaji visual. Kata-kata yang banyak digunakan sebagai simbol/lambang dalam lirik tembang Sunda Cigawiran adalah kata yang menggambarkan atau menyimbolkan hal yang berhubungan dengan keagamaan. Secara umum, gaya bahasa yang terdapat dalam lirik tembang Sunda Cigawiran menggunakan bahasa yang umum, hiperbola, dan konotatif. Lirik tembang Sunda Cigawiran secara umum mempunyai tema yang berkaitan dengan keagamaan. Rasa yang paling banyak terdapat dalam lirik tembang Sunda Cigawiran adalah rasa takut. (3) Lirik tembang Sunda Cigawiran memiliki nilai etnopedagogik seperti Prilaku Nyunda Trisilas, Catur Jatidiri Insan, Gapura Panca Waluya, dan Moral Kemanusiaan.

\section{DAFTAR RUJUKAN}

Sudaryat, Yayat. 2015. Wawasan Kesundaan. Bandung: Universitas Pendidikan Indonesia.

Budiwati, Dewi Suryati. 2003. Tembang Sunda Cigawiran: Sosialisasi NilaiNilai Budaya dan Fungsi Tembang Sunda Cigawiran pada Kehidupan Masyarakat Cigawir. (Tésis). Jurusan Pendidikan Seni Tari Universitas Negeri Semarang, Semarang.

Siswantoro. 2014. Metode Penelitian Sastra: Analisis Struktur Puisi. Yogyakarta: Pustaka Pelajar.

Sugiyono. 2013. Metode Penelitian Kuantitatif Kualitatif dan $R \& D$. Bandung: Alfabeta.

\section{UCAPAN TERIMA KASIH}

Terima kasih dan penghargaan yang setinggi-tingginya penulis sampaikan kepada semua pihak yang telah membantu penelitian ini. Kepada penyunting Jurnal Lokabasa pun penulis menyampaikan terima kasih atas dimuatnya tulisan ini. 